\section{$16^{\circ}$ \\ ERGODESIGN USIHC CINAHPA}

$16^{\circ}$ Ergodesign - Congresso Internacional de Ergonomia e Usabilidade de Interfaces Humano Tecnológica: Produto, Informações Ambientes Construídos e Transporte

$16^{\circ}$ USIHC - Congresso Internacional de Ergonomia e Usabilidade de Interfaces Humano Computador

CINAHPA | 2017 - Congresso Internacional de Ambientes Hipermídia para Aprendizagem.

\title{
A CIDADE VISTA PELAS MÃOS: UMA PROPOSTA DE ROTA INCLUSIVA
}

\section{THE CITY VISITED BY HANDS: AN INCLUSIVE ROUND PROPOSAL}

\author{
Ester Jorge ${ }^{1}$, M.Sc \\ Ana Maria $\mathrm{Maciel}^{2}$, M.Sc. \\ Vilma Villarouco ${ }^{3}, \mathrm{PhD}$. \\ (1) UFPE \\ e-mail: arq.estercosta@gmail.com \\ (2) UFPE \\ e-mail: anamariamaciel@yahoo.com.br
}

(3) UFPE

e-mail: villarouco@hotmail.com

Palavras-chave: acessibilidade; mobilidade e representação espacial.

Este estudo tem como principal objetivo uma proposta inclusiva para o Centro da Cidade do Recife. Para isso, foi desenvolvido uma rota inclusiva com abrangência de vias importantes e seus elementos de ligação, as pontes. A proposta destaca o uso dos mapas táteis, ferramenta que auxilia a informação espacial e facilita a orientação e mobilidade urbana para os deficientes visuais.

Key-words: accessibility; mobility; Spatial representation.

This study has as main objective an inclusive proposal for the Center of the City of Recife. For this, a pilot route was developed with three neighborhoods and its main linking elements, the bridges. The proposal highlights the use of tactile maps, a tool that helps spatial information and facilitates urban orientation and mobility for the visually impaired.

\section{Introdução}

Todas as cidades devem proporcionar a seus usuários o direito de usufruir com plena capacidade em seus espaços. O ir e vir sem barreiras, abrange dois conceitos fundamentais para a inclusão social: mobilidade urbana e acessibilidade. De acordo com a Lei 12.587/12, a mobilidade urbana é a condição em que se realizam os deslocamentos de pessoas e cargas no espaço urbano. Perpassa pelas condições físicas das vias de acesso e possíveis deslocamentos. Para 


\section{$16^{\circ}$ \\ ERGODESIGN USIHC CINAHPA}

Silva (2009), é um instrumento de planejamento urbano que engloba sistema viário, meios de transportes e trânsito; vai além do que um indicador de capacidades individuais de desempenhar viagens, ou um dado numérico.

Quando entendida na dimensão do indivíduo, a mobilidade deve considerar grupos distintos: pedestres, ciclistas, usuários de coletivos, assim como pessoas com deficiências permanentes ou temporárias.

Assim, para a concepção de uma cidade com alto índice de mobilidade, devem-se ter espaços acessíveis, não apenas no sentido restrito de estar livre de barreiras, mas proporcionar a todos os usuários, a condição de usufruir dos espaços urbanos com segurança, conforto e autonomia.

Nos centros históricos, o desafio é ainda maior, pois traz uma carga de simbolismos, identidades e valores históricos que se somam as transformações espaciais. Para Del Rio (1993) as áreas centrais possuem uma importância que está profundamente ligada às lógicas histórica e sócio-espacial e é por isto que elas se destacam na percepção e vivência de qualquer cidade.

Assim, para corroborar com o fomento de propostas voltadas para cidades acessíveis e com mobilidade, este estudo propõe uma rota inclusiva. $O$ recorte espacial se dá no Centro da cidade do Recife, onde se considerou vias que compõem um trecho de tecido urbano importante, destacado por seus pontos de lazer.

As rotas acessíveis, que se caracterizam como trajetos contínuos, desobstruídos e sinalizados, conectando ambientes externos ou internos de espaços e edificações. Quando externa, uma rota acessível pode incorporar estacionamentos, calçadas rebaixadas, faixas de travessia de pedestres, rampas, escadas, elevadores, etc. (ABNT,2016)

A proposta é inclusiva, mas direciona-se para um grupo de usuários em específico: deficientes visuais, considerados o grupo que mais sofre marginalização quanto a ocupação e uso dos $16^{\circ}$ Ergodesign - Congresso Internacional de Ergonomia e Usabilidade de Interfaces Humano Tecnológica: Produto, Informações Ambientes Construídos e Transporte

$16^{\circ}$ USIHC - Congresso Internacional de Ergonomia e Usabilidade de Interfaces Humano Computador

CINAHPA | 2017 - Congresso Internacional de Ambientes Hipermídia para Aprendizagem.

espaços da cidade. Segundo dados do IBGE (2010), no Brasil, entre as deficiências investigadas, a deficiência visual apresenta a maior incidência, sendo declarada por $18,8 \%$ da população. Apesar destas constatações, ainda são insipientes os projetos urbanos que tenham uma concepção inclusiva para todas as deficiências. Deve-se ressaltar ainda, que o uso da visão é considerado o mais importante para a percepção do espaço em que vivemos. Assim, proporcionar aos deficientes visuais elementos que compensem a ausência da visão, através dos outros sentidos é decisivo para a inclusão destes na cidade.

Neste sentido, foi utilizada uma ferramenta que auxilia a informação espacial e facilita a orientação e mobilidade, os mapas táteis. Para Venturini (2007), esse recurso oferece condições para que os deficientes visuais formem esquemas espaciais de ambientes, antecipando suas decisões e minimizando a complexidade e pontualidade destes esquemas.

\section{As pontes do Centro da cidade: elementos de mobilidade e acessibilidade urbana.}

Desde sua origem, o Recife é marcado por dois elementos fisiográficos que se tornaram peculiares na paisagem da cidade: os arrecifes e os rios Capibaribe e Beberibe. O primeiro que deu nome à cidade, é relatado por Bento Teixeira (XVI), em sua Prosopopéia, como: "Uma cinta de pedra, inculta e viva, ao longo da soberba e larga costa, onde quebra Netuno a fúria esquiva. "Com relação ao segundo elemento destacamos o rio Capibaribe, "elemento marcante na construção e na estruturação dessa cidade" (MELO,2003, p.49).

Assim, visando superar os elementos fisiográficos componentes do sítio onde se originou a cidade do Recife, foram construídos alguns elementos morfológicos, visando atender a expansão urbana, decorrente das relações sócio-espaciais da época.

Dentre estes elementos, estão as pontes, definidas por Ferreira (1976, p.1112) como: "Qualquer elemento que estabelece ligação, contato, comunicação ou transição entre pessoas ou coisas." Estes se tornaram imprescindíveis para a expansão 


\section{$16^{\circ}$ \\ ERGODESIGN USIHC CINAHPA}

$16^{\circ}$ Ergodesign - Congresso Internacional de Ergonomia e Usabilidade de Interfaces Humano Tecnológica: Produto, Informações Ambientes Construídos e Transporte

$16^{\circ}$ USIHC - Congresso Internacional de Ergonomia e Usabilidade de Interfaces Humano Computador

CINAHPA | 2017 - Congresso Internacional de Ambientes Hipermídia para Aprendizagem. da cidade, pois viabilizaram a continuação do traçado urbano sobre os rios, facilitando em diversos aspectos o cotidiano de seus usuários. Assim, O Centro da Cidade é recortado por pontes que marcam as transformações históricas do Recife.

Foi dentro deste contexto, que se deu a construção das pontes Santa Isabel e Buarque de Macedo, construídas entre os séculos XVII e XIX, as quais fazem parte da rota inclusiva deste estudo. Ver (Figura 1 e 2).

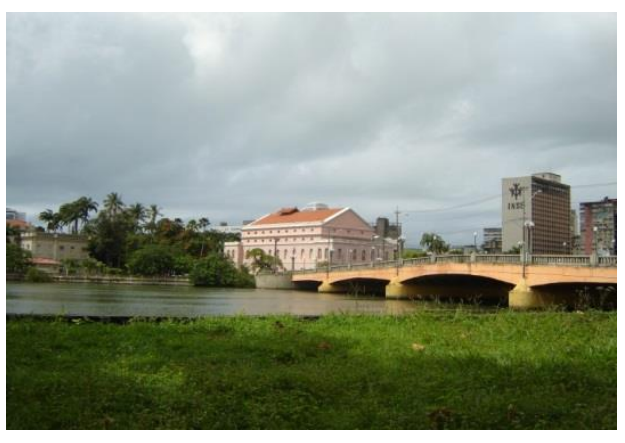

Figura 1: Ponte Santa Isabel Fonte: Jorge,2007

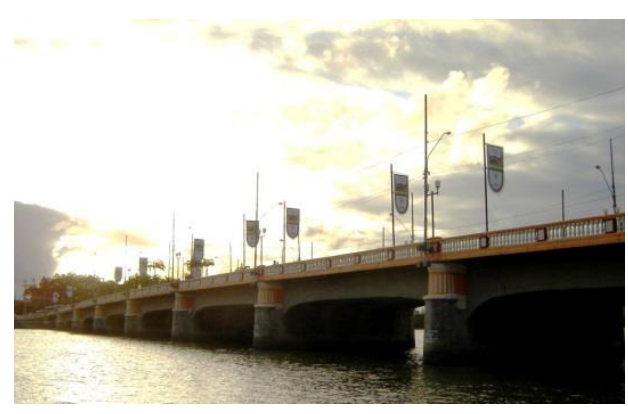

Figura 2: Ponte Buarque de Macedo Fonte: Jorge, 2007.

A importância destas pontes no centro da cidade do Recife pode ser constatada através de produtos culturais como relatos de viajantes, iconografias, poesias, jornais e da historiografia, contribuindo para que elas se tornem perenes na memória coletiva. Desde a concepção projetual tiveram como principal função a acessibilidade e mobilidade dos percursos de seus usuários.

\section{A Orientação espacial na cidade}

Para Bins Ely (2000), o ato de se deslocar e estar orientado requer do deficiente visual uma compreensão de como se constrói as representações espaciais. Pode-se definir primeiramente que a orientação espacial é um fenômeno estático, onde se referencia mentalmente as partes do todo, ou seja, os ambientes de um espaço para poder se situar no mesmo. Assim, a construção das referências espaciais, se dá, de acordo com a apreensão dos dados, gradativamente. Ainda segundo Bins Ely (2000), orientar-se espacialmente perpassa pela habilidade de representar mentalmente as características espaciais de um arranjo físico e a situar-se dentro da mesma. A esta representação mental dá-se o nome de "mapa cognitivo" ou "mapa mental". Assim, entende-se que estes mapas são uma sequência de visões percebidas de um ambiente que se somam e totalizam a representação espacial.

Ressalta-se que o mapa mental, apesar de conter informações espaciais, não pode ser considerado um mapa geográfico. Pela maneira subjetiva como é concebido e percebido tem características esquemáticas e possui sempre diferenças de distâncias e escalas.

Assim, do ponto de vista cognitivo, a orientação espacial se baseia na habilidade em formar mapas mentais. Uma pessoa é considerada bem orientada espacialmente se elaborar um adequado mapa mental do ambiente e souber situar-se dentro desta imagem. Em outras palavras, para uma simples locomoção, é preponderante a composição de alguma forma de imagem mental.

A orientação espacial, no sentido de movimento orientado ou wayfinding, elucida como os indivíduos se deslocam nos ambientes, ou como encontram seu destino, mesmo num espaço desconhecido. Este processo de orientação envolve, não apenas a construção de mapas cognitivos, mas uma série de processos mentais. Segundo Passini e Shields (1987), envolve três estágios: o processamento da informação, a tomada de decisão e a execução da decisão.

Para a realização deste processo serão projetados mapas táteis, denominados de ajuda técnica, pois 


\section{$16^{\circ}$ \\ ERGODESIGN USIHC CINAHPA}

$16^{\circ}$ Ergodesign - Congresso Internacional de Ergonomia e Usabilidade de Interfaces Humano Tecnológica: Produto, Informações Ambientes Construídos e Transporte

$16^{\circ}$ USIHC - Congresso Internacional de Ergonomia e Usabilidade de Interfaces Humano Computador

CINAHPA | 2017 - Congresso Internacional de Ambientes Hipermídia para Aprendizagem. são equipamentos especialmente projetados para melhorar a funcionalidade da pessoa com deficiência ou com mobilidade reduzida, favorecendo a autonomia pessoal, total ou assistida.

\section{Os mapas táteis: uma ferramenta facilitadora para a inclusão de deficientes visuais.}

Em 2010, o IBGE constatou que no Brasil, entre as deficiências investigadas, a deficiência visual é a que apresenta a maior incidência. Dentre estas, considera -se que 506.377 não enxergam de modo algum, 6.056.533 tem grande dificuldade, e 29.211.482 possuem alguma dificuldade de enxergar.

Para a delimitação do grupamento de deficientes visuais, cegos e portadores de visão subnormal, são analisadas duas escalas oftalmológicas: acuidade visual, aquilo que se enxerga a determinada distância e campo visual, a amplitude da área alcançada pela visão. Assim, pode-se definir os níveis de deficiência visual em: baixa visão moderada 20/80; baixa visão severa 20/200; baixa visão profunda 20/500; cegueira 20/1250; cegueira total na percepção da luz. Uma pessoa é considerada cega

A deficiência visual limita e algumas vezes, até impede algumas habilidades, fazendo com que o portador de deficiência visual se sinta marginalizado e excluído de simples ações cotidiana. Esta situação, afeta o PDV e as pessoas que se relacionam com ele: familiares, amigos e outros. Para Rabasco (2009), “... dependem muitas vezes da vontade e da ação de outros para ampliar progressivamente seu conhecimento do mundo. Sua educação na busca em conseguir uma autonomia está baseada em outorgar-lhes as habilidades que lhes permitam viver na sociedade que os rodeia e a compreender suas regras." (RABASCO, 2009, p. 406).

Para Veras e Vargas (2004), O deficiente visual, assim como as demais pessoas, passa por um processo sensorial e cognitivo, onde a recepção de informações a todo instante, lhe permite reconhecer o universo ao seu redor e o capacita para a mobilidade. Contudo, a acuidade visual, resulta no aumenta do esforço cognitivo, fazendo com que o deficiente utilize recursos de memórias, representação espacial, tomada de decisões e outras habilidades que sobrecarregam o processo.

Para o aumento da inclusão de deficientes visuais no meio urbano, são utilizados diversos recursos, dentre eles o mapa tátil. Em Nogueira (2008), a Cartografia Tátil é definida como um ramo específico da cartografia que se ocupa da confecção de mapas e outros produtos cartográficos que possam ser lidos por pessoas cegas e com baixa visão. Assim, os produtos resultantes desta cartografia, podem ser considerados como recursos da tecnologia assistiva, pois segundo Almeida e Loch (2005,p.41), a tecnologia assistiva é "todo o arsenal de recursos e serviços que contribuem para proporcionar ou ampliar habilidades funcionais de pessoas com restrições sensório-motoras e, consequentemente, promover vida independente e inclusão".

Para a confecção de uma mapa tátil, devem ser consideradas as variáveis gráficas que serão utlilizadas para a construção como: a textura, o tamanho, a forma e a altura. Fazendo a devida redução de escala para os fenômenos geográficos que podem ser representados por pontos, linhas e áreas. Para o deficiente visual, a decodificação através dos símbolos táteis e geográficos deve ser imediata. (LOCH e ALMEIDA, 2008).

A elaboração de mapas táteis pode ser artesanal ou através de softwares. A primeira forma se inicia com o desenho dos mapas para a confecção da matriz e a colagem de diferentes materiais, como cortiça, emborrachados, barbantes e material de bijuteria. A segunda utiliza um software de desenho gráfico para imprimir o mapa convencional o qual servirá como referência para o mapa tátil. Esta impressão é feita em materiais específicos, como papel microcapsulado, acetato ou braillon (LABTATE, 2008).

Deve-se ressaltar a importância do contraste de cores, para as pessoas com baixa visão em detrimento da diminuição da acuidade visual. Para 


\section{$16^{\circ}$ \\ ERGODESIGN USIHC CINAHPA}

Gomes Filho (2000), o contraste trabalha contra a tendência do equilíbrio absoluto, desequilibra, sacode, estimula e atrai a atenção.

\section{Proposta e Percurso Metodológico}

Para o desenvolvimento deste trabalho foi escolhida a pesquisa qualitativa, na tentativa de aproximar o pesquisador dos aspectos subjetivos que permeiam o universo do portador de deficiência visual. No desenvolvimento metodológico se configuram etapas teóricas e práticas, divididas em cinco fases:

(1) Fase de estruturação teórica: É a construção do embasamento teórico, através do levantamento bibliográfico e documental do referencial teórico;

(2) Fase de análise do espaço: observação in loco do pesquisador e de um portador de deficiência visual, levantamento iconográfico de fotos e mapas do espaço;

(3) Fase de interpretação e confecção: Análise dos dados e a confecção do protótipo dos mapas táteis para teste posterior;

(4) Fase de teste e adaptações: Nesta fase os deficientes visuais utilizarão o mapa tátil e farão um passeio acompanhado para diagnosticar as vantagens e possíveis adaptações deste recurso;

(5) Fase Conclusiva: onde serão feitas as considerações finais sobre o processo de construção deste trabalho.

\section{Delimitação da Rota Inclusiva}

A escolha deste espaço da cidade se deu pela necessidade de tornar mais acessível vias com edificações de grande interesse histórico, e por ser um trajeto marcado pelo Marco Zero da cidade. (Fig. 03) Com a implantação do Plano Nacional dos Direitos da Pessoa com deficiência-Viver sem limites (Decreto $N^{o} 7.612$ ), estão sendo fomentados os projetos inclusivos nos Centros históricos. O bairro do Recife é marcado por um traçado urbano e edificações (Fig. 04) ricos de acontecimentos históricos, mas ainda insipientes $16^{\circ}$ Ergodesign - Congresso Internacional de Ergonomia e Usabilidade de Interfaces Humano Tecnológica: Produto, Informações Ambientes Construídos e Transporte

$16^{\circ}$ USIHC - Congresso Internacional de Ergonomia e Usabilidade de Interfaces Humano Computador

CINAHPA | 2017 - Congresso Internacional de Ambientes Hipermídia para Aprendizagem. em atender os usuários de maneira plena, sem

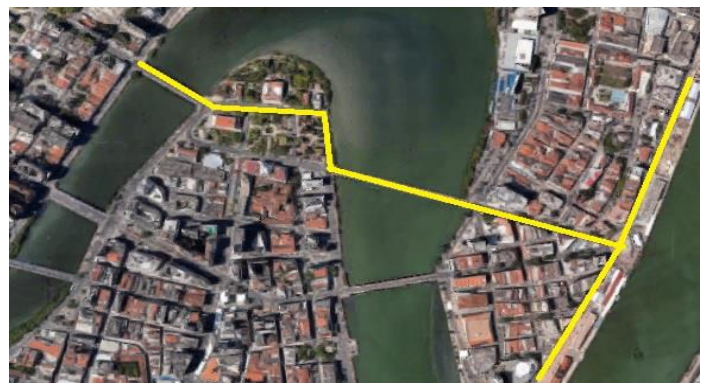

barreiras.
Figura 3: Rota Inclusiva

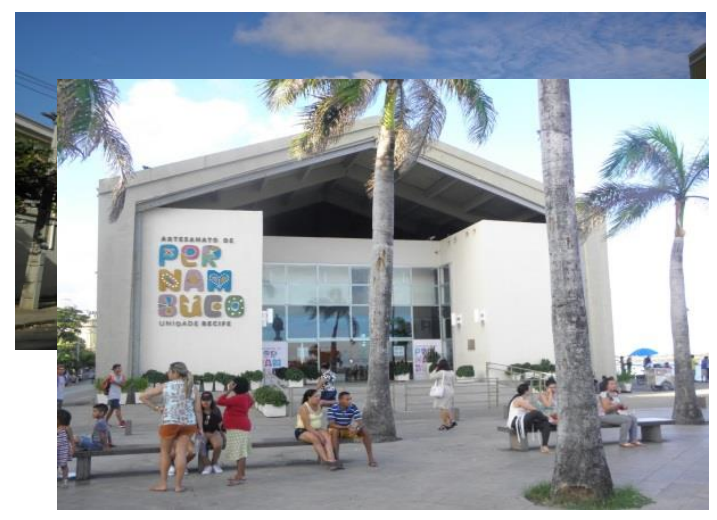

Fonte: Jorge, 2017.
Figura 4: Edifício histórico ( Torre Malakoff) Fonte: Jorge, 2017

Figura 5: Centro de Artesanato de Pernambuco Fonte: Jorge, 2017

Realização:




\section{$16^{\circ}$ \\ ERGODESIGN USIHC CINAHPA}

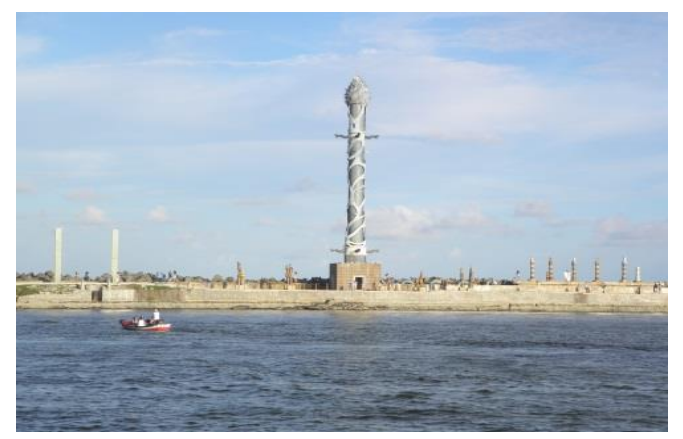

Figura 6: Parque de Esculturas Fonte: Jorge, 2017

\subsection{Construção dos mapas táteis}

Para a construção dos mapas táteis para a rota "Recife visto pelas mãos", utilizaremos os conhecimentos adquiridos em outro projeto de pesquisa intitulado "Mapas táteis em espaços abertos" e que tem por objetivo criar acessibilidade e incluir as pessoas com deficiência nos parques da cidade do Recife.

O mapa tátil foi elaborado a partir da plotagem da UNIBASE municipal onde se pode identificar os elementos edificados, as rotas das pistas de pedestres, bicicletas e os diversos acessos presentes.

Para a confecção foi utilizada uma base de papelão de alta densidade, revestido de EVA na cor vermelha, com as delimitações das pistas: branco, azul e amarelo, para diferenciar os usos ( cooper, skate e bicicletas). Para a melhor compreensão tanto dos deficientes visuais de baixa visão, quanto dos de visão zero, foi acrescentado uma legenda em braille dos principais elementos edificados para facilitar a orientação dos futuros usuários .

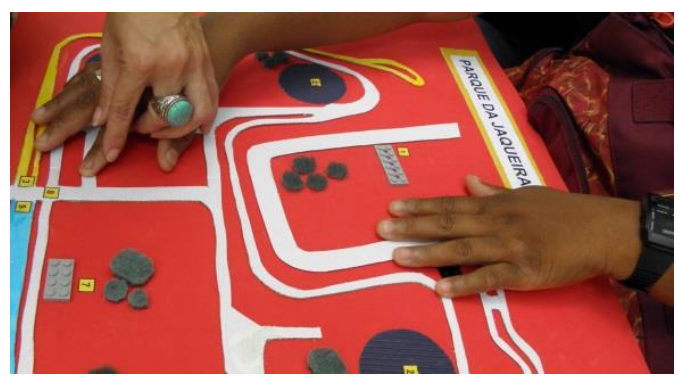

$16^{\circ}$ Ergodesign - Congresso Internacional de Ergonomia e Usabilidade de Interfaces Humano Tecnológica: Produto, Informações Ambientes Construídos e Transporte

$16^{\circ}$ USIHC - Congresso Internacional de Ergonomia e Usabilidade de Interfaces Humano Computador

CINAHPA | 2017 - Congresso Internacional de Ambientes Hipermídia para Aprendizagem.

Figura 3: Mapa Tátil

Fonte: Jorge, 2016.

\subsection{Recomendações}

Através da aplicação dos instrumentos de pesquisa pode-se enumerar um conjunto de problemas e possíveis recomendações.

\begin{tabular}{|l|l|}
\hline Problemas Encontrados & Recomendações \\
\hline - Postes e desníveis sem & $\bullet$ Instalar Mapas táteis \\
proteção; & nas pontes e edifícios \\
- Ausência de referenciais & históricos; \\
nos percursos; & $\bullet$ Instalar guias de \\
- Tampas de & balizamento; \\
concessionárias & $\bullet$ Indicar o nivelamento \\
desniveladas; & das rampas conforme \\
- Rampas inacessíveis; & recomendações da NBR \\
- Ausência de sinalização & $9050 / 2015 ;$ \\
sonora; & $\bullet$ Propor postes com \\
- Ausência de piso podo & sinal sonoro; \\
tátil nos passeios; & $\bullet$ Implantar piso \\
- Ausência de faixas de & podotátil nos passeios; \\
travessia elevadas. & $\bullet$ Implantar faixas de \\
& travessia elevadas. \\
\hline
\end{tabular}

\section{Considerações Finais}

Embora os temas da mobilidade e acessibilidade venham sendo debatidos por várias esferas governamentais e não governamentais, ainda encontramos grandes lacunas seja na definição de diretrizes projetuais para proposição de rotas acessíveis seja em especial na inserção de um instrumento como o mapa tátil. E é nesse sentido que a presente pesquisa busca dar sua contribuição em especial para o público deficiente visual.

Percebeu-se que é possível inserir recursos que contribuem para a acessibilidade do ambiente construído, garantindo uma boa condição de percepção e apropriação do espaço com segurança e autonomia, independente das limitações dos usuários.
Realização:

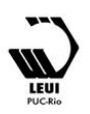




\section{$16^{\circ}$ \\ ERGODESIGN USIHC CINAHPA}

$16^{\circ}$ Ergodesign - Congresso Internacional de Ergonomia e Usabilidade de Interfaces Humano Tecnológica: Produto, Informações Ambientes Construídos e Transporte

$16^{\circ}$ USIHC - Congresso Internacional de Ergonomia e Usabilidade de Interfaces Humano Computador

CINAHPA | 2017 - Congresso Internacional de Ambientes Hipermídia para Aprendizagem.
Como já foi informado, a escolha dos bairros São José, Boa Vista e Recife se deu em função desse território ter grande importância para identidade da população recifense e para a economia turística.

Para tanto o trajeto (rota) proposta para o bairro denominado Recife visto pelas mãos apresentou-se como objeto empírico de grande interesse por todos os que tiveram acesso a proposta, deficientes visuais ou não, uma vez que a implantação de rotas acessíveis contribui para a definição de um percurso seguro, oferecendo a oportunidade de um uso igualitário. De toda forma rotas acessíveis atuam como um guia para percorrer os espaços para qualquer novo usuário destacando os principais elementos edificados.

\section{Bibliografia}

BINS ELY, Vera Helena Moro; DISCHINGER, Marta; MATTOS, Melissa Laus; RIEDTMAN, Louise; ANTONIOLLI, Maicon. Acessibilidade e Orientabilidade no Terminal Rodoviário Rita Maria. Florianópolis, 2001. 137p. Relatório de Pesquisa - Programa Especial de Treinamento (PET/SESu), Universidade Federal de Santa Catarina.

DEL RIO, Vicente. Introdução ao Desenho Urbano no Processo de Planejamento. São Paulo: Pini, 2000.

FERREIRA, Aurélio Buarque de Holanda. Novo Dicionário da Lingua Portuguesa. Rio de Janeiro: Nova Fronteira. 1976.

MELLO, Evaldo Cabral de. Canoas do Recife. In:SOUTO MAIOR, Mário ; DANTAS

SILVA,Leonardo. O Recife: quatro séculos de sua paisagem. Recife: Fundaj, Ed. Massangana; Prefeitura da Cidade do Recife, 1992.

MORRIS, J.M.; Dumble, P.L.; Wigan, M.R. 1979. Accessibility indicators for transport planning. Transportation Research, Part A, v.13, n.2, p.91109.

SILVA, Claúdio Oliveira da. Cidades concebidas para o automóvel: mobilidade urbana nos planos diretores posteriores ao Estatuto da Cidade. (Dissertação de mestrado). Faculdade de Arquitetura eUrbanismo, Universidade de Brasília. Brasília, 2009. 